DOI: https://doi.org/10.24867/08GI14Ivancevic

\title{
UNAPREĐENJE SKLADIŠNOG POSLOVANJA IMPLEMENTACIJOM WMS U INSTITUTU ZA RATARSTVO I POVRTARSTVO
}

\section{IMPROVEMENT OF WAREHOUSE IN "INSTITUT ZA RATARSTVO I POVRTARSTVO” WITH IMPLEMENTATION OF WMS}

\author{
Tijana Ivančević, Fakultet tehničkih nauka, Novi Sad
}

\section{Oblast - LOGISTIKA}

Kratak sadržaj - Predmet rada jesu osnovni pojmovi logistike, sa naglaskom na značaj skladišnih procesa u logistici. Primenom inženjerske metode Ishikawa dijagram, identifikovani su glavni uzroci koji utiču na proces skladištenja u Institutu za ratarstvo $i$ povrtarstvo. $\mathrm{Na}$ osnovu rezulata dobijenihi iz Ishikawa dijagrama, predloženo je unapređenje skladišnog poslovanja u preduzeću, kupovinom WMS i RFID sistema.

Ključne reči: Logistika, Skladište, Ishikawa dijagram, Unapređenje, WMS, RFID

Abstract - In this paper, basic concepts of logistics are presented, with an emphasis on importance of warehouse processes in logistics. By applying engineering method Ishikava diagram, the main causes that affect warehouse processes at the Institute of Field and Vegetable Crops, were identified. Based on the resolution obtained from the Ishikava diagram, it was suggested to improve the enterprise warehouse business by purchasing WMS and RFID systems.

Keywords: Logistics, Warehouse, Ishikawa diagram, Improvement, WMS, RFID

\section{UVOD}

Upravljanje skladištem deo je poslovne logistike, koja se bavi optimizacijom troškova i vremena skladištenja i kretanja proizvoda od proizvodnog preduzeća preko trgovaca na malo i veliko sve do krajnjeg korisnika. Da bi se bolje razumeli skladišni sistemi kao sastavni deo logističkih procesa, neophodno je prvo proučiti i opisati logistiku u celosti. Analiza logističkih procesa kroz istoriju daje uvid u razvoj skladišnih procesa i sistema kroz vreme. Osnovne funkcije skladišta su prijem robe, smeštaj i čuvanje, zatim izdavanje i otprema robe.

Skladišta se razlikuju prema načinu izgradnje i stepenu njihove mehanizacije. Različite delatnosti zahtevaju različite vrste skladišta i načine skladištenja. Osnovni zadatak skladišta je očuvanje vrednosti i kvaliteta robe, kao i osiguranje nesmetanog i neprekidnog toka poslovanja. Skladišta su ograđeni ili neograđeni prostori, pokriveni ili nepokriveni, koji se koriste za čuvanje sirovina, poluproizvoda, ili gotovih proizvoda.

\section{NAPOMENA:}

Ovaj rad proistekao je iz master rada čiji mentor je bio dr Stevan Milisavljević, vanr. prof.

\section{LOGISTIKA}

Pojam „logistika“ u literaturi se upotrebljava u različitim značenjima i ima širok opis primene. U etimološkom pogledu koren reči potiče od grčke reči logos koja ima sledeća značenja: razum, odnos, pojam, razlog. Logistika je interdisciplinarna oblast sistema nauka koja obuhvata organizaciona rešenja, infrastrukturu, resurse, procese i ekonomsku podršku, radi realizacije zadatih ciljeva, kroz celokupni životni ciklus proizvoda. Logistika je sve ono što prati osnovnu delatnost na koju se odnosi i bez koje se osnovna delatnost ne može izvoditi ili se izvodi sa velikim poteškoćama. Logistika je od suštinskog značaja za svaku organizaciju. Logistički sistem predstavlja skup elemenata tehničke, tehnološke, organizacione, ekonomske i pravne prirode s ciljem optimizacije tokova materijala, roba, informacija, energije i ljudi na određenom području radi ostvarenja najvećih ekonomskih efekata.

\section{SKLADIŠTENJE}

\subsection{Pojam i značaj skladišta}

Skladište predstavlja određeni prostor koji je namenjen za čuvanje i smeštaj robe koja je predmet poslovanja preduzeća. Može se još definisati kao prostor za privremeno čuvanje raznih materijalnih sredstava u komadnom, rasutom i tečnom obliku, koji će posle izvesnog vremena biti uključeni u reprodukciju, transport ili potrošnju. Predstavlja fiksnu tačku u lancu snabdevanja gde preduzeće čuva sirovine, poluproizvode ili gotove proizvode $\mathrm{u}$ različitim vremenskim periodima. Skladište se sastoji od tri osnovna dela: prostora, opreme i ljudi.

Prostor omogućava čuvanje robe u različitim vremenskim intervalima i različitim odnosima ponude i potražnje. Skladišnu opremu čine uređaji za rukovanje materijalima, police za odlaganje, oprema za prenos i sistem za obradu informacija. Oprema olakšava kretanje proizvoda, čuvanje i praćenje. Vrsta opreme koja se koristi u skladištu zavisi o vrste proizvoda koji se skladšte. Ljudi predstavljaju ključni činilac skladišta. Prostor i oprema ne znače ništa bez stručnih ljudi.

Razlozi za postojanje skladišta su:

- postizanje ekonomičnosti u transportu, pri kretanju većih količina,

- obezbeđuju se popusti na veće količine pri kupovini,

- čuvanje dobavljača,

- praćenje promena tržišnih uslova,

- podrška JIT programima, kroz integrisani logistički sistem. 
Skladišta omogućavaju prihvat robe na kraju određenog proizvodnog ili transportnog procesa na mestima pogodnim za smeštaj, da bi se pod što povoljnijim uslovima ta roba mogla dalje uključiti u neki drugi proces.

Kao glavni razlozi za skladištenje materijala u preduzeću javljaju se:

- Potreba za skladištenjem sirovina;

- Potreba za skladištenjem poluproizvoda;

- Potreba za skladištenjem gotovih proizvoda i

- Potreba za skladištenjem alata.

\subsection{Osnovni procesi skladištenja}

Osnovni procesi u skladištu uključuju čuvanje, premeštanje i prenos informacija.

Čuvanje predstavlja primarnu funkciju skladišta i odnosi se na fizičko raspolaganje proizvodom unutar skladišta. Čuvanje može biti privremeno ili polutrajno.

Da bi se omogućilo pravilno skladištenje proizvoda, premeštanje je nužno i odvija se u četiri odvojena područja:

1. Prijem, pregled i sortiranje dolazeće robe od prevoznika i obavljanje provere kvaliteta i kvantiteta.

2. Prenos robe sa prijemnih platformi i premeštanje do pojedinih mesta za čuvanje unutar skladišta.

3. Priprema za isporuku tj. izbor naručenih proizvoda (komisioniranje), a ispunjenje narudžbine kupaca uključujući, proveru, pakovanje i transport do otpremnih rampi.

4. Isporuka robe prema kupcu određenim načinom prevoza.

Proces prenos informacija, javlja se $\mathrm{u}$ isto vreme dok se proizvod prima, premešta i skladišti. Menadžment uzima informacije o nivou zaliha, lokaciji zaliha, protoku, iskorišćenosti prostora i druge informacije neophodne za uspešno funkcionisanje skladišta. Informacije se koriste za procenu učinka skladištenja putem ispitivanja stepena iskorišćenosti opreme, produktivnosti rada i iskorišćenosti prostora.

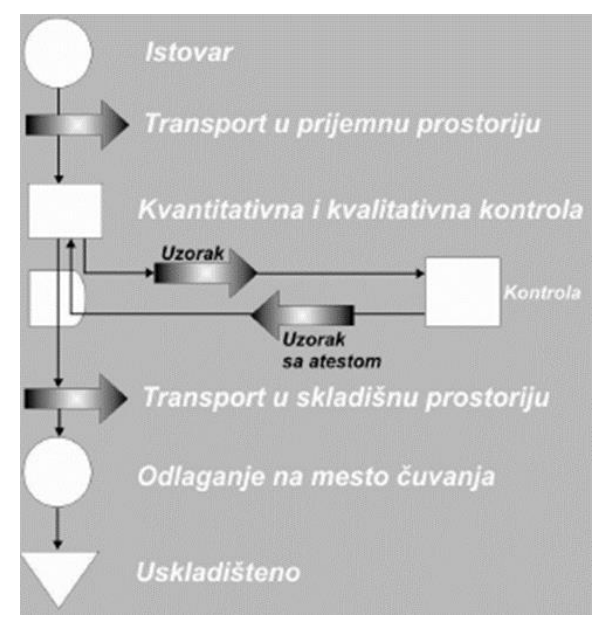

Slika 1 - Skladišni procesi

\subsection{Mesto i uloga skladišta u logističkim sistemima}

Skladištenje se pojavljuje kao funkcija, logistička aktivnost i sistem koji realizuje čuvanje robe. Integralni je deo svakog logističkog sistema i ima nezamenljivu ulogu u povezivanju proizvodnje, transporta i potrošnje. Sva preduzeća u kojima se odvijaju logistički procesi smatraju se logističkim sistemom.
Skladište ima višestruku ulogu u lancu snabdevanja. Obično se posmatra kao mesto za čuvanje zaliha, ali skladište danas predstavlja mnogo dinamičniji sistem u kome kretanje robe često predstavlja dominantnu aktivnost. Služi kao mesto za objedinjavanje transporta, omogućuje nagomilavanje zaliha, olakšava proizvodnju, pruža sigurnost u slučaju prekida rada pogona, prekida isporuke dobavljaču ili zastoja u transportu itd.

Glavna funkcija skladišnog podsistema u logističkom sistemu jeste čuvanje zaliha proizvoda, kako bi se obezbedila sinhronizacija procesa koji prethode skladištenju i procesa koji se realizuju posle skladištenja.

\section{PODACI O PREDUZEĆU}

Institut za ratarstvo i povrtarstvo je osnovan 1938. godine odlukom Ministarstva poljoprivrede Kraljevine Jugoslavije. Tada je oformljena Poljoprivredna i kontrolna stanica u Novom Sadu iz koje je nastao današnji Institut.

Osnovna i primenjena istraživanja, koja su osnovna delatnost Instituta, usmerena su na stvaranje sorti i hibrida ratarskih, povrtarskih kao i velikog broja krmnih, industrijskih, lekovitih i začinskih biljaka. Institut razvija i tehnologiju gajenja sopstvenih sorti i hibrida.

Rezultati se prenose odmah u praksu, na više načina: preko semena, kao tehnologija obrade zemljišta, kao tehnologija gajenja pojedinih sorti i hibrida ili preko zaštite pojedinih sorti i hibrida.

Institut za ratarstvo i povrtarstvo ima moćan naučni tim od preko 100 istraživača, od čega je 70 doktora nauka. Njima asistira preko 300 visokoobrazovanih i radnika različitih profila, što je garancija kvaliteta svega što Institut nudi - semena, tehnologije, obrazovanja i usluga. Uzlaznu liniju razvoja Institut danas uspešno nastavlja održavanjem Sistema upravljanja kvalitetom prema Internacionalnom standardu ISO 9001, i Sistema upravljanja zaštitom životne sredine prema ISO 14001.

Pored naučnog dela, Institut razvija i komercijalni. Od pre nekoliko godina, Institut je plasirao i novu robnu marku „NS seme” koja je već znak prepoznavanja i sinonim za kvalitet i dobar prinos.

\section{ANALIZA SKLADIŠNOG POSLOVANJA 5.1. Proces skladištenja}

Preduzeće koristi softver Microsoft Dynamics NAV za svoje svakodnevno poslovanje. Microsoft Dynamics NAV predstavlja rešenje za upravljanje poslovanjem za organizacije male i srednje veličine koje automatizuje i međusobno usklađuje poslovne procese. $\mathrm{S}$ obzirom na to da je veoma prilagodljiv i sadrži mnoštvo funkcija, Microsoft Dynamics NAV omogućava preduzećima da upravljaju svojim poslovanjem, uključujući finansije, proizvodnju, prodaju, isporuku, upravljanje projektima, usluge i još mnogo toga. Preduzeća mogu na jednostavan način da dodaju funkcije koje odgovaraju regionu u kom posluju i imaju prilagođenu podršku čak i za uskospecijalizovane delatnosti.

Prijem robe počinje dobijanjem ,naloga za prijem” na kojem se vide svi podaci koji definišu robu. Magacioner preuzima nalog za prijem i vrši raspodelu robe po paletnim mestima. Sistem prepoznaje da li se u skladištu 
već nalazi slična roba i na osnovu parametara koji mu se definišu i podataka o robi daje predlog paletnih mesta na koje treba odložiti robu. Na magacioneru ostaje izbor da li će prihvatiti ponudu ili će sam izvršiti odabir paletnih mesta.

Nakon odabira lokacija na koje treba smestiti robu štampa se lista skladištenja na kojoj se vide svi podaci o robi, kao i brojevi paletnih mesta na koja se roba treba odložiti. Izborom opcije ,štampa nalepnica” na termalnom štampaču vrši se štampa nalepnica sa bar kodom na kojima se nalaze podaci o robi i paletnom mestu gde treba da bude odložena.

Izdavanje robe se vrši na osnovu „naloga za izdavanje“ koje magacioner dobija kroz instalirani softver. Nakon što prihvati navedeni nalog magacioneru se automatski pojavljuju na monitoru računara svi podaci o robi koju treba isporučiti. Softver sam određuje lokacije sa kojih je potrebno uzeti određenu robu, kao i njihov redosled $u$ zavisnosti od više kriterijuma koji su zadati. Magacioneru dalje ostaje samo da oštampa „listu za izdavanje“ koju dalje preuzima viljuškarista.

Slično kao i kod prijema robe, viljuškarista, treba da ide od lokacije do lokacije redom kojim su palete sa robom poređane na displeju ručnog računara i izvrši izuzimanje navedene robe iz regala. Kada dođe na odgovarajuću lokaciju viljuškarista skenira bar kod lokacije da potvrdi da je na dobroj lokaciji (čuje se karakterističan zvuk koji potvrđuje ili opominje ako je na pogrešnoj lokaciji), zatim skenira bar kod na paleti sa robom (takođe zvučna potvrda ili opomena) i vrši izdvajanje robe iz regala.

Preskladištenje robe $u$ ovakvim magacinima je redovna mera. Naime, najčešće se najniža etaža koristi za komisioniranje, a ostale za smeštaj celih paleta. To znači da se roba koja se izdvaja, pod uslovom da nije reč o kompletnim paletama, izdvaja isključivo sa ovih etaža. S obzirom da softver vodi računa o stanju robe na svakoj lokaciji, zadavanjem minimalne količine određene robe na lokaciji određuje se trenutak kada će doći do preskladištenja. Kada je neki od viljuškarista slobodan, dobija nalog za preskladištenje određene palete sa više etaže na nižu.

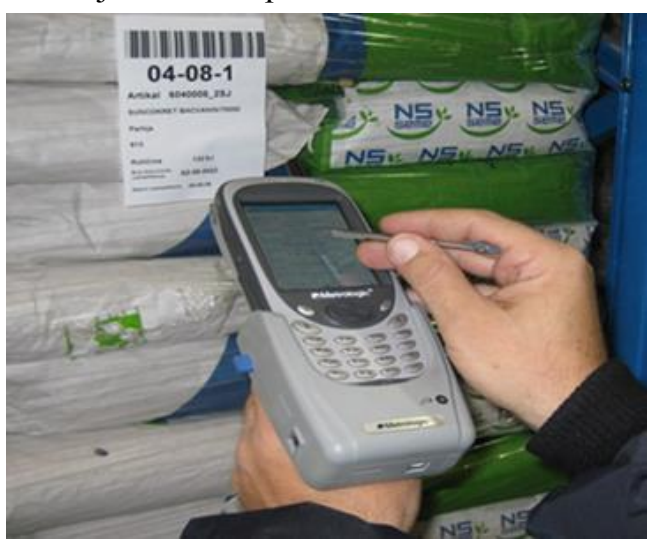

Slika 2. Ručni računar sa skenerom

\subsection{Dijagram uzroka i posledice - Ishikawa dijagram}

Ishikawa dijagram je dobio naziv po svom tvorcu, Kaoru Ishikawi. Doktor Ishikawa je bio profesor na Univerzitetu u Tokiju pedesetih godina kada su u Japanu počele da se uvode teorije i principi o kvalitetu u inženjerstvu. Njegovi saradnici su koristili dijagrame kako bi rasporedili faktore koji možda imaju uticaj na aktivnosti njihovog istraživanja. Nakon toga, 1953. godine, Kaori Ishikawa je prvi put upotrebio dijagram kako bi rezimirao mišljenja inženjera $\mathrm{u}$ postrojenju, pošto su diskutovali o problemu kvaliteta. To je bila prva poznata upotreba dijagrama uzroka i posledica, kakvog ga danas poznajemo i koji se danas koristi za primenu. Dijagram je bio toliko koristan da su ga korporacije širom Japana, ubrzo nakon prve primene, koristile redovno kako bi ispitale koji su mogući uzroci problema.

Ovaj dijagram prikazaje sve uzroke koji dovode do određene posledice. Posledica je određeni ishod procesa rada koje imaju dve kategorije U i IZVAN granica dozvoljenih odstupanja. Takođe posledica može biti i željeni rezultat nekog procesa. Uzroci su skup uslova okoline koji rezultuju određenom stanju- ishodu procesa rada.

Pomoću Ishikawa metode utvrđeni su svi uzroci koji utiču na proces skladištenja u preduzeću.

\section{PREDLOZI ZA UNAPREĐENJE SKLADIŠNOG POSLOVANJA}

\subsection{Warehouse Management System - WMS}

Warehouse management system (WMS) je informacioni sistem upravljanja skladištem koji ima za cilj da osigura efikasnu kontrolu kretanja robe kroz skladište. Tipična WMS funkcionalnost podrazumeva nadzor nad prijemom, skladištenjem, komisioniranjem i isporukom. Mogućnost sistema da kontroliše i optimizuje kretanje robe je zasnovana na logističkim pravilima i sposobnosti sistema da $\mathrm{u}$ realnom vremenu obezbedi inofrmacije o statusu i lokaciji robe, popunjenosti skladišta, prijemu i zahtevima za isporuku.

Ovaj sistem može se koristiti kao deo ERP (Enterprise resource planning) sistema ili kao poseban sistem. WMS je softver projektovan za kontrolu i upravljanje procesom transporta, rukovanja, prerade i skladištenja roba/materijala. Glavna svrha WMS sistema za upravljanje skladištem je minimalizacija grešaka, maksimizacija produktivnosti i ljudskog rada, te maksimizacija iskorišćenosti opreme i prostora.

Kao glavna komponenta WMS-a pojavljuje se softver, koji služi za optimizaciju skladišnih i sa skladištem povezanih operacija. WMS osim softverskog dela skladišnog poslovanja, koriste i namensku opremu (hardver), koja se koristi u skladišnom poslovanju. WMS sistemi za upravljanje skladištem koriste automatsku identifikaciju i tehnologiju prikupljanja podataka, poput bar-code skenera, mobilnih računara, wireless mrežnu infrastrukturu, identifikaciju putem radio frekvencija (RFID - radio frequency identification) kako bi efektivno pratili tok materijala i proizvoda kroz skladište.

Stepen sofisticiranosti WMS-a varira od jednostavnih sistema za kontrolu lokacija materijala u skladištu do sistema koji optimizuju uslugu korisnicima, prostor, ljudski rad i korišćenje opreme u skladištu. Danas u pravilu WMS upravlja svim skladišnim aktivnostima, a povezan je i razmenjuje podatke s centralnim sistemom preduzeća za upravljanje poslovanjem. Na tržištu se može naći preko 400 proizvođača WMS softvera, koji rade na velikim 
računarima, kao što je IBM AS/400, pa do malih PC računara, koji rade na Windows 95 operativnom sistemu.

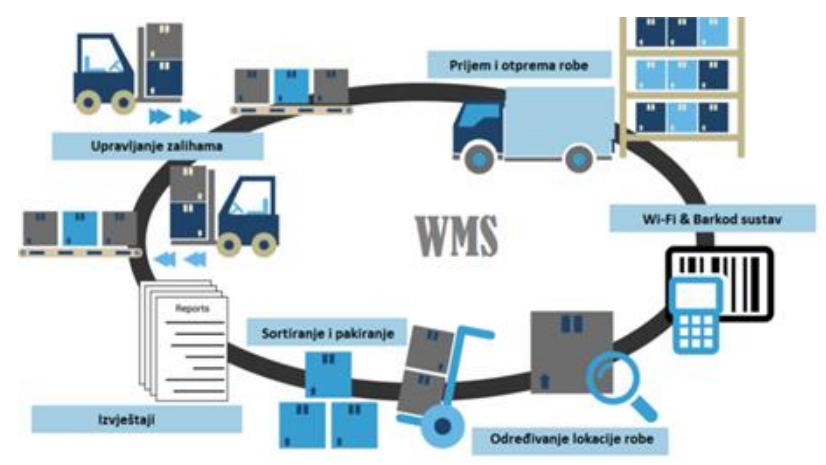

Slika 3. Prikaz WMS sistema

\subsection{RFID sistem}

Efektivni procesi WMS-a omogućavaju brži unos podataka i obradu za ulazne, izlazne i unutrašnje skladišne operacije. S obzirom da se WMS bazira na upotrebi bar koda, bilo bi ga beznačajno uvoditi bez RFID (Radio Frequency) uređaja koji su ručni ili montirani na viljuškar. RFID je sistem daljinskog slanja i prijema podataka pomoću RFID pločica/odašiljača. RFID pločica je izuzetno mali objekat koji se može zalepiti ili ugraditi u željeni proizvod. RFID čitač šalje elektromagnetne talase, pri čemu antena transpondera mora biti podešena na odgovarajuću frekvenciju tako da može da prima ove talase.

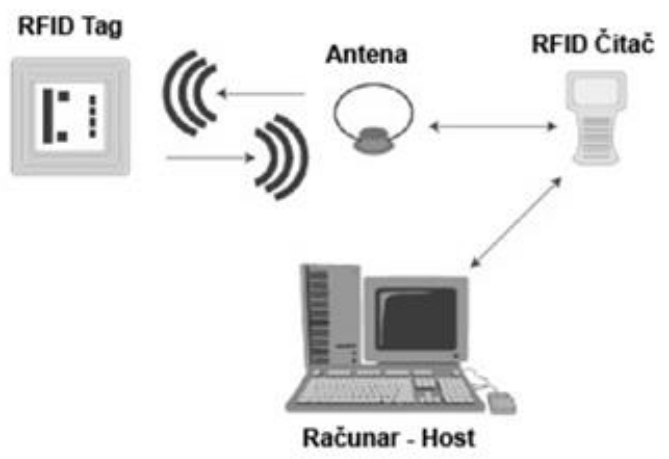

Slika 4. RFID sistem

Kada se završi prijem radio signala, RFID tag istog trenutka šalje jedinstveni identifikacioni kod i/ili niz podataka, ranije smeštenih u mikročipu transpondera. RFID čitač prevodi primljene radiotalase u odgovarajući digitalni podatak, a zatim prenosi taj podatak računaru i omogućava njegovu dalju obradu. Da bi uređaji radili, potrebno je po skladištu postaviti prijemnike koji primaju i prenose podatke iz više RFID uređaja prema glavnom računalu. RFID uređaji se koriste za mobilni unos i snimanje podataka u skladištu. Svaki proizvod mora imati svoj bar kod koji se skenira RFID uređajima i zatim se podaci šalju, preko prijemnika, u glavni računar. Korišćenjem bar kodova i RFID uređaja povećava se efektivnost skladišnih lokacija, greške prilikom unosa podataka su manje i vreme potrebno za obavljanje poslova u skladištu je smanjeno, jer se sve može prikupiti RFID uređajem bez potrebe za ručnim unosom podataka i skupljanjem narudžbi pomoću papira.

\section{ZAKLJUČAK}

Razvoj tržišta i njegova globalizacija stvorili su okruženje koje zahteva brzu reakciju na potrebe korisnika. Da bi kompanija uspešno poslovala potrebno je da pored kvaliteta proizvoda obezbedi i njegovu laku i brzu dostupnost krajnjem potrošaču. Za ispunjenje ovakvih potreba tržišta neophodno je obezbediti alate za efikasno i pouzdano upravljanje poslovnim aktivnostima koji omogućavaju brzo i kvalitetno donošenje odluka. Osnovu svakog informacionog sistema u savremenim kompanijama predstavlja neko od dostupnih ERP softvera. Fokus ovakvih rešenja je finansijski aspekt poslovanja, što je predstavljalo ograničenje $u$ daljem razvoju i proširenju funkcionalnosti. Vremenom ovo ograničenje uslovilo je neophodnost stvaranja specijalizovanih softverskih rešenja, kao što je u oblasti lanca snabdevanja - Warehouse Management System.

WMS rešenja predstavljaju specijalizovana softverska rešenja fokusirana na kontrolu kretanja robe u realnom vremenu uz najbolje moguće korišćenje raspoloživih resursa unutar skladišnog sistema. WMS sistem mora pružiti potpunu informacionu podršku procesima skladištenja, mora pratiti i beležiti sve aktivnosti u vremenu njihovog događanja uz istovremenu dostupnost i osiguranje povratnih informacija $u$ svrhu planiranja proizvodnje, optimizacije zaliha i planiranja poslovne strategije na tržištu. Bar-kod sistem identifikacije i radio-frekvencijski sistem (RFID) sastavni su delovi savremenih WMS sistema u "skladištima bez papira".

\section{LITERATURA}

[1] Prof. dr Dušan Regodić (2014), „Logistika - Lanci snabdevanja", Beograd

[2] Lambert i Stock, (1993), „Strategic logistics management", New York

[3] D. Stanivuković, B. Kamberović, R. Maksimović i dr. (2012), "Metode i tehnike unapređenja procesa rada",

Fakultet tehničkih nauka, Novi Sad

[4] Mitrović, S., Melović, B. (2013), "Principi savremenog menadžmenta", Fakultet tehničkih nauka, Novi Sad

[5] Božić, V., Aćimović, S., Rakić, S. (2009), Poslovna logistika, Valjevo

[6] Vukićević, S. (1995) „Skladišta“, Beograd

\section{Kratka biografija:}

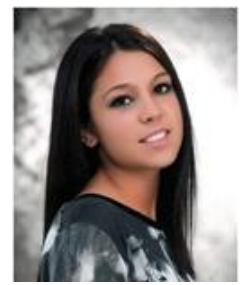

Tijana Ivančević rođena je u Novom Sadu 1994. god. Master rad na Fakultetu tehničkih nauka iz oblasti Logistike odbranila je 2019.god.

kontakt: tijanaivancevic6@gmail.com 